\title{
Enhancement of Liquid and Gaseous Biofuels Production From Agro-Industrial Residues After Thermochemical and Enzymatic Pretreatment
}

\author{
Georgia Antonopoulou ${ }^{1}$, Anastasios Kampranis ${ }^{2,3}$, Ioanna Ntaikou ${ }^{1 *}$ and \\ Gerasimos Lyberatos ${ }^{1,4}$
}

\begin{abstract}
${ }^{1}$ Laboratory of Environmental Biotechnology, Institute of Chemical Engineering Sciences, Foundation for Research and Technology, Patras, Greece, ${ }^{2}$ Department of Agricultural Technology, School of Agricultural Technology and Food and Nutrition Technology, Technological Educational Institute (TEl) of Western Greece, Patras, Greece, ${ }^{3}$ School of Agriculture, University of loannina, Arta, Greece, ${ }^{4}$ School of Chemical Engineering, National Technical University of Athens, Athens, Greece
\end{abstract}

OPEN ACCESS

Edited by:

Anne Tremier,

Irstea-Centre de Rennes, France

Reviewed by:

Helen Treichel,

Universidade Federal da Fronteira

Sul, Brazil

M. Angeles de la Rubia,

Autonomous University of

Madrid, Spain

*Correspondence: Ioanna Ntaikou

ntaikou@iceht.forth.gr

Specialty section:

This article was submitted to

Waste Management in

Agroecosystems,

a section of the journal

Frontiers in Sustainable Food Systems

Received: 30 June 2019 Accepted: 02 October 2019 Published: 24 October 2019

Citation:

Antonopoulou G, Kampranis A, Ntaikou I and Lyberatos G (2019) Enhancement of Liquid and Gaseous

Biofuels Production From

Agro-Industrial Residues After

Thermochemical and Enzymatic

Pretreatment.

Front. Sustain. Food Syst. 3:92. doi: 10.3389/fsufs.2019.00092
In the present study, the effect of thermo-chemical pretreatment and enzymatic hydrolysis on the saccharification and the further bioconversion of two different types of lignocellulosic agro-industrial residues to bioethanol and methane, was investigated. The residues used were the sunflower straw (SS) and the cracked olive stones (OS) remaining after the olive oil production process. Biomasses were subjected to simultaneous chemical and thermal pretreatment using either dilute $\mathrm{H}_{2} \mathrm{SO}_{4}$ or dilute $\mathrm{NaOH}$ aqueous solutions of concentrations $0.5,1$, and $1.5 \%(\mathrm{w} / \mathrm{v})$, at $121^{\circ} \mathrm{C}$ for $60 \mathrm{~min}$. The saccharification of the complex carbohydrates due to pretreatment was determined in terms of the sugars released, and the effect of each pretreatment was evaluated statistically. The effect of the enzymatic hydrolysis of the biomasses using commercial cellulolytic enzymes on saccharification was also assessed and statistically evaluated in terms of different enzymatic loadings. Subsequently, the pre-treated wastes were used as a substrate for methane and ethanol production using mixed methanogenic consortia and the yeast Pachysolen tannophilus, respectively.

Keywords: pretreatment, sunflower straw, olive stones, bioethanol, methane

\section{INTRODUCTION}

Nowadays, increasing energy needs have led to a critical reduction of crude oil supplies worldwide, which, together with the effects of global warming, render the identification, and exploitation of renewable energy as the sole viable alternative for the future. The replacement of conventional fuels by biofuels has been proposed as a reliable solution to meet energy demands in the transportation sector and has been supported by European Directives, which required partial substitution of gasoline and diesel by biofuels up to $5.75 \%$ in 2010 and up to $10 \%$ (Directive 2009/28/EC) by 2020 (Galbe and Zacchi, 2007; Ferro et al., 2015). Among biofuels, methane, biohydrogen, and bioethanol provide promising alternatives, since they are non-toxic and different biomass-based feedstocks of various composition and origin, including agro-industrial wastes, can be exploited for their production. 
Agro-industrial residues represent an abundant and almost zero cost feedstock with high organic content, mainly complex carbohydrates, despite being unable to be directly bioconverted to biofuels. This is due to the fact that carbohydrates of plant material are in the form of the complex structure of lignocellulose (cellulose, hemicellulose, and lignin) that need to be fractionated and hydrolyzed in order to be exploitable via biological processes (Antonopoulou et al., 2015a). Such fractionation can be achieved by applying proper pretreatment methods. The selection of a proper pretreatment method can result in breaking of the lignin seal of lignocellulose and, in some cases, depolymerization of cellulose and/or hemicellulose, with subsequent liberation of simple sugars (hexoses and pentoses) that can be assimilated by microorganisms and converted to biofuels. Thus, this results in enhanced conversion efficiency of the feedstock and increased productivities and yields of metabolic products.

The aim of the present study was to investigate the impact of thermochemical pretreatment on the saccharification and the further bioconversion of lignocellulosic wastes toward bioethanol and methane. Two types of wastes with different characteristics and origin were selected i.e., sunflower straw (SS) and olive stones (OS) generated as a byproduct during olive oil production process. Both biomasses were subjected to simultaneous chemical and thermal pretreatment using either dilute $\mathrm{H}_{2} \mathrm{SO}_{4}$ or dilute $\mathrm{NaOH}$ aqueous solutions of concentrations $0.5,1$, and $1.5 \%(\mathrm{w} / \mathrm{v})$, at $121^{\circ} \mathrm{C}$ for $60 \mathrm{~min}$. The organic load was $5 \% \mathrm{w} / \mathrm{v}$ in all cases. The direct saccharification effect was determined and the effect of each pretreatment was evaluated statistically, whereas, the effect of the enzymatic hydrolysis of the biomasses using commercial cellulolytic enzymes on saccharification was also assessed and statistically evaluated in terms of different enzymatic loadings. Subsequently, the pre-treated wastes were used as a substrate for ethanol and methane production using the yeast Pachysolen tannophilus and mixed methanogenic consortia, respectively.

\section{MATERIALS AND METHODS}

\section{Feedstocks Olive Stones}

Olive stones (OS) were obtained from a three-phase olive mill of Patras, Greece. OS were collected immediately after the olive extraction process, and were stored at $-21^{\circ} \mathrm{C}$ until their use. In order to be used for the experiments of the present study, biomass was dried at $70^{\circ} \mathrm{C}$ until stabilization of weight, and subsequently subjected to mechanical treatment using a stainless steel grinder mill, then sieved to a powder of $<1 \mathrm{~mm}$ diameter. The milled OS was mixed thoroughly in order to be homogenized, and its composition was estimated to be: $98.19 \pm 0.17 \%$ total solids (TS), $49.66 \pm 2.12 \%$ total carbohydrates, $0.02 \pm 0.00 \%$ free sugars, $8.88 \pm 1.12 \%$ residual oil, $13.0 \pm 0.8 \%$ o phenolic compounds, proteins $3.72 \pm 0.24 \%$, and $2.62 \pm 0.14 \%$ ash. The TS and volatile solids (VS) of the raw OS prior to drying and milling were also estimated and their values were $47.95 \pm 1.39$ and $46.76 \pm$ $1.11 \%$, respectively.

\section{Sunflower Straw}

SS was collected after seed harvesting. Prior to use, samples were grinded with the stainless-steel grinder mill and were sieved to a powder of $<1 \mathrm{~mm}$ diameter. In the sequel, SS powder was dried at $55^{\circ} \mathrm{C}$ and used for the experiments. The milled SS composition was $95.89 \pm 0.36 \%$ TS, $55.33 \pm 0.45 \%$ total carbohydrates, 3.45 $\pm 0.15 \%$ sugars, $1.72 \pm 0.22 \%$ proteins, and $10.5 \pm 1.1 \%$ ash. The TS and VS of the raw SS prior to drying was $87.03 \pm 1.45$ and $78.57 \pm 1.09 \%$, respectively.

\section{Pretreatment}

\section{Thermochemical}

Thermochemical pretreatment was performed in triplicate at both acidic and alkaline conditions. Specifically, milled SS and OS were suspended to aquatic solutions of $\mathrm{H}_{2} \mathrm{SO}_{4}$ and $\mathrm{NaOH}$ of $0.5,1$, and $1.5 \%$ concentration (w/v) so as to correspond to $5 \%$ initial solids loading ( $5 \mathrm{~g} / 100 \mathrm{~mL}$ of added liquid). They were suspended for $1 \mathrm{~h}$ at $121^{\circ} \mathrm{C}$ in borosilicate glass serum bottles of $160 \mathrm{ml}$ total volume, sealed with rubber septa and crimpled with aluminum seals (Wheaton). Suspension was then characterized in terms of free sugars content, measured as glucose equivalents, and the saccharification yield of each pretreatment method was estimated as g sugars per $\mathrm{kg}$ initial TS of SS or OS.

\section{Enzymatic}

The enzymatic pretreatment was performed in triplicate using a mixture of commercial enzymes, i.e., Celluclast 1.5 L (Cellulase from Trichoderma reesei, ATCC 26921) and Novozyme 188 (Cellobiase from Aspergillus niger) at a ratio of (3:1), for $24 \mathrm{~h}$ at $50^{\circ} \mathrm{C}$ and $\mathrm{pH}$ of 4.8 , as proposed by Antonopoulou and Lyberatos (2013). Different concentrations of the enzymatic mixtures were used $(20,30,40,50,100,200,300,400$, and $500 \mathrm{FPU}$ of Celluclast $1.5 \mathrm{~L} / \mathrm{gTS}$ ) and the effect on saccharification was evaluated by measuring soluble carbohydrates in the hydrolyzate and expressed in glucose equivalents.

\section{Fermentation Tests for Bioethanol Production Microorganism}

For the fermentation experiments, the yeast $P$. tannophilus strain, DSMZ 70352, was used. The yeast was stored at $4^{\circ} \mathrm{C}$ in slant cultures using a medium with the following composition (in g/L): malt extract 20; myco-peptone 1; d-glucose 20; agar 15 . Inoculation was performed under sterile conditions with precultures kept overnight using the microbial pellet that was obtained via centrifugation of a pre-culture aliquot of volume corresponding to $10 \%$ of the final culture volume.

\section{Bioethanol Production}

Fermentations were performed in triplicate in sterile $250 \mathrm{~mL}$ Erlenmeyer flasks at $30^{\circ} \mathrm{C}$ and mechanical agitation of $100 \mathrm{rpm}$. Each Erlenmeyer flask contained $100 \mathrm{~mL}$ of medium, with $5 \%$ initial solids loading, using the whole biomass slurry obtained after pretreatment, as substrate. Since P. tannophilus does not have fibrolytic properties, all cultures were also supplemented with Celluclast 1.5 L (30 FPU/g TS) and Novozyme 188 at a ratio of (3:1), under sterile conditions. 


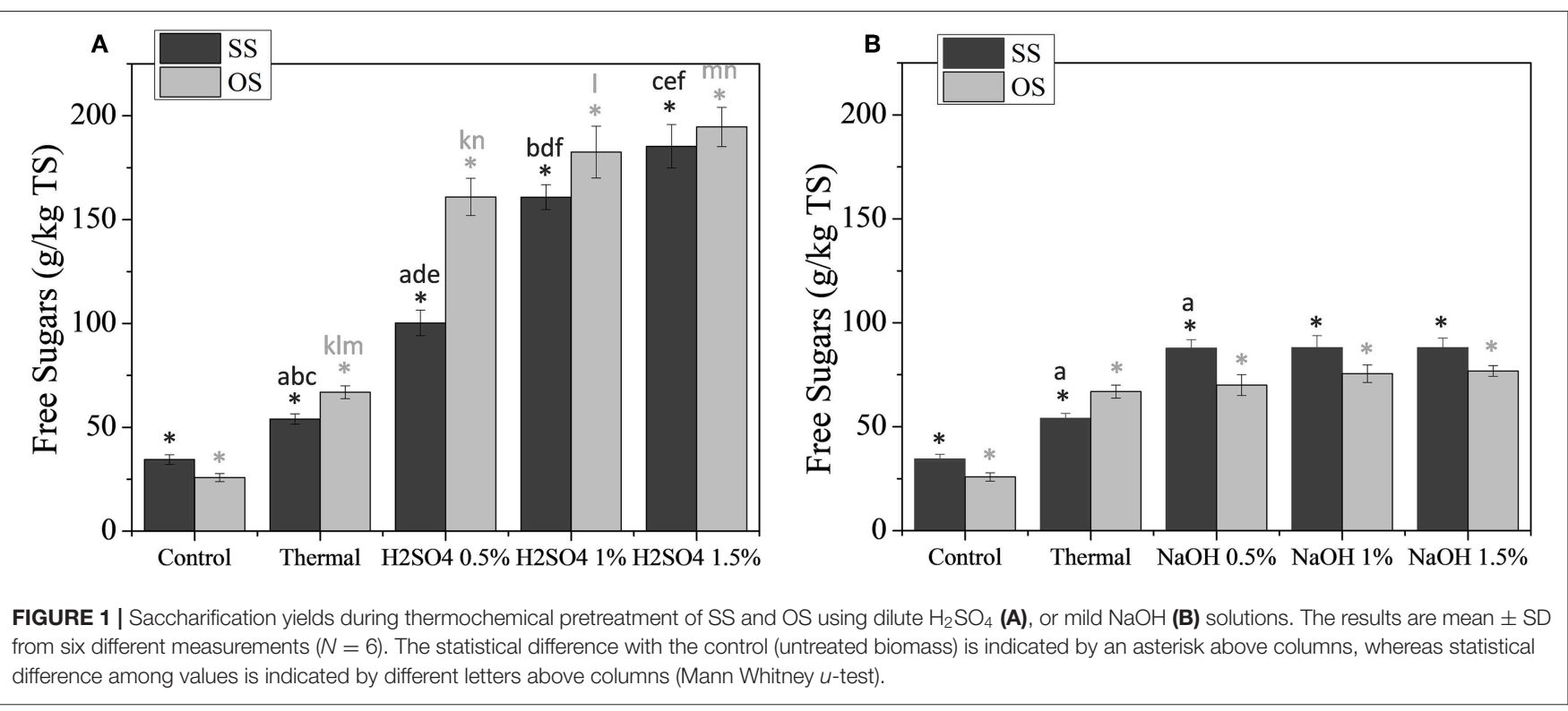

\section{Biochemical Methane Production (BMP Tests)}

BMP tests were conducted in duplicate at $35^{\circ} \mathrm{C}$ as described in Antonopoulou and Lyberatos (2013). The anaerobic sludge that was used had the following characteristics: $\mathrm{pH}$ : 7.7, total chemical oxygen demand (T.COD): $34.3 \mathrm{~g} / \mathrm{L}$, dissolved COD (d.COD): $0.45 \mathrm{~g} / \mathrm{L}$, total suspended solids (TSS): $25.7 \mathrm{~g} / \mathrm{L}$, and volatile suspended solids (VSS): $12.8 \mathrm{~g} / \mathrm{L}$.

\section{Analytical Methods}

The measurements of Total Solids (TS), Volatile Solids (VS), oil content (using the Soxhlet extraction method). For the determination of crude protein, the Total Kjeldahl Nitrogen (TKN) was estimated according to Standard Methods (American Public Health Association et al., 1995) and was then multiplied 6.25 (Monlau et al., 2012). Carbohydrates were quantified calorimetrically at 520 (Josefsson, 1983). The enzymatic activity of cellulase (Celluclast 1.5L) was estimated according to Ghose (1987). For the quantification of ethanol, the protocol was described by Antonopoulou et al. (2016) via HPLC-RI (Dionex). The gas composition produced in methane was quantified via GC-TCD as described in Antonopoulou and Lyberatos (2013). The measurement of the $\mathrm{pH}$ was done using a HANNA ( $\mathrm{pH}$ 211) $\mathrm{pH}$-meter with a HANNA electrode (HI 1230).

\section{Statistical Analysis}

The statistical analysis of the data was performed using the SPSS Inc. 17 software package for SS and OS, separately. After checking for homogeneity of the variance (Levene's test of equality of error variances), the significant difference among each treatment was assessed non-parametrically, using the Mann Whitney $u$-test ( $p$ $<0.05$, ANOVA).

\section{RESULTS AND DISCUSSION}

\section{Pretreatment}

\section{Thermochemical}

In Figure 1, the effect of acid (A) and alkaline (B) pretreatment on the saccharification yields of the substrates are illustrated. For comparison reasons of the acid and alkaline pretreatments, the same scale was used in both graphs even though yields during acid pretreatment were quite higher. As shown, the effect of $\mathrm{H}_{2} \mathrm{SO}_{4}$ on the saccharification exhibited similar profiles for SS and OS, with the saccharification yields of acid pretreated biomasses being significantly different from those of the control and the thermally treaded biomasses. For higher concentration of the acid, there seems to be an increasing tendency of the release of sugars for both substrates. However, statistical analysis revealed that this is only valid in the case of SS, for which the saccharification of $0.5 \% \mathrm{H}_{2} \mathrm{SO}_{4}$ is significantly different that those of 1 and $1.5 \%$. On the contrary, saccharification of OS was not estimated to be statistically different for increasing acid concentrations. The maximum saccharification was estimated to be $185.32 \pm 10.45$ and $194.64 \pm 9.45$ $\mathrm{g} / \mathrm{kg} \mathrm{TS}$, for the pretreatment with $1.5 \% \mathrm{H}_{2} \mathrm{SO}_{4}$ for $\mathrm{SS}$ and OS, respectively.

According to the literature, the main reaction that is induced by acid pretreatment is the hydrolysis of hemicellulose and especially of xylan, because glucomannan is more stable (Carrere et al., 2016). Taking into account that the holocellulosic content of SS and OS was estimated to be $\sim 50 \%$, it can thus be assumed that almost $40 \%$ of the complex carbohydrates of the SS and also OS are actually hydrolyzed in the conditions that were tested, thus indicating that almost all hemicellulose of the substrates was actually solubilized. Similar results were obtained in the study of Senkevich et al. (2012), in which olive mill solid residues were thermochemically pretreated with dilute $\mathrm{H}_{2} \mathrm{SO}_{4}$ at $130^{\circ} \mathrm{C}$ for $45 \mathrm{~min}$. 


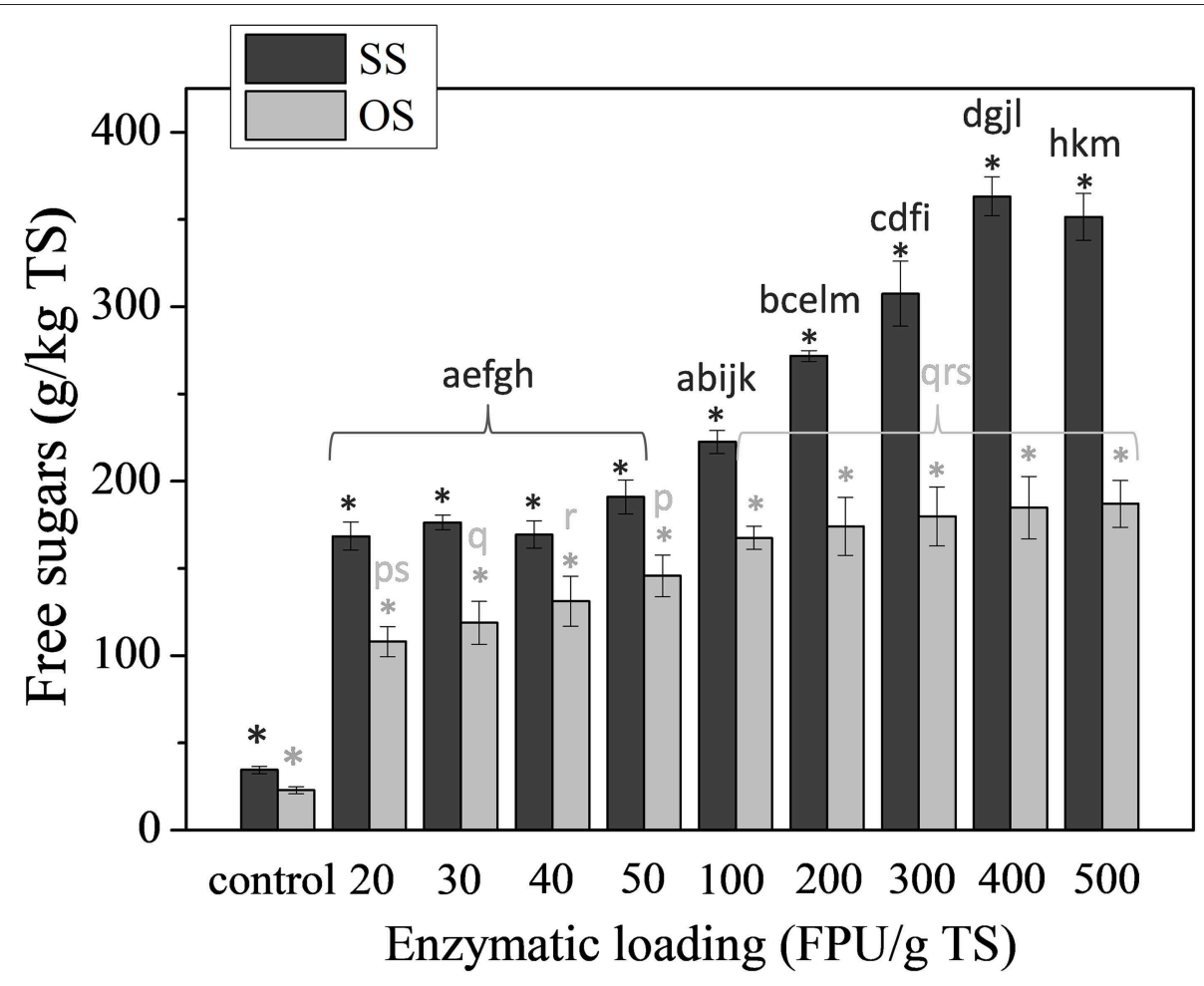

FIGURE 2 | The effect of enzymatic treatment at different enzyme concentrations (20-500 FPU/g TS) using the mixture of commercial enzymes, on the saccharification of carbohydrates of SS and OS. The results are mean \pm SD from six different measurements $(N=6)$. The statistical difference with the control (untreated biomass) is indicated by an asterisk above columns, whereas statistical difference among values is indicated by different letters above columns (Mann Whitney $u$-test).

Regarding the effect of $\mathrm{NaOH}$ on the saccharification of SS and OS during thermochemical pretreatment, it is apparent that it was considerably milder than those of $\mathrm{H}_{2} \mathrm{SO}_{4}$. As shown in Figure 1B, the maximum amount of sugars released for each substrate was estimated as $87.70 \pm 4.18$ and $76.82 \pm 4.63 \mathrm{~g} / \mathrm{kg} \mathrm{TS}$, for OS pretreated with $0.5 \% \mathrm{NaOH}$ and SS pretreated with $1.5 \%$ $\mathrm{NaOH}$, respectively, with the increasing concentration of alkaline having a negligible effect on the saccharification. In all cases, a statistically significant difference of saccharification during alkaline pretreatment was noted only with the control only and not among for the different concentration of $\mathrm{NaOH}$ used. The only exception noted was for SS pretreated with $0.5 \% \mathrm{NaOH}$, for which there was also a statistically significant difference with the thermally pretreated SS. Those findings are in agreement with previous studies during which alkaline pretreatment was applied to various types of lignocellulosic wastes and residues aiming at the facilitation of biofuels production (Senkevich et al., 2012; Antonopoulou and Lyberatos, 2013; Antonopoulou et al., 2015a). It is indeed reported that alkaline pretreatment breaks the intermolecular ester bonds between the lignin-carbohydrates matrix and modifies the biomass structure, resulting in the solubilisation of mainly lignin, whereas holocellulosic content is affected to a lower degree (Kumar and Sharma, 2017). At the same time, alkaline pretreatment results in structural changes of cellulose, such as swelling, increase of its surface area and porosity and a decrease in its crystallinity, thus making it vulnerable to enzymatic hydrolysis (Monte et al., 2018). As such, the increase of the yield of the free sugars of alkaline pretreated lignocellulose should indeed be expected during a subsequent hydrolysis, rather than directly after pretreatment, as also shown by Senkevich et al. (2012) in the case of pretreated olive mill residues.

\section{Enzymatic}

The effect of the enzymatic treatment on the saccharification of the substrates is illustrated in Figure 2. Different enzymatic loadings, ranging from $20 \mathrm{FPU}$ of Celluclast $1.5 \mathrm{~L} / \mathrm{gTS}$ to 500 FPU of Celluclast $1.5 \mathrm{~L} / \mathrm{gTS}$, were tested and their effect on the saccharification of the substrate was assessed after $48 \mathrm{~h}$ of treatment. As expected, the concentration of sugars in the suspensions of enzymatically treated biomasses were significantly different from the respected controls, even in the case of the lowest enzymatic loading, since hydrolysis actually solubilizes the complex carbohydrates that they contain, whereas the sugars content of the control is actually negligible. It is quite interesting though that the hydrolysis profiles of SS and OS were quite different for increasing enzymatic loadings. As such, it seems that in the case of SS, for loadings from 20 FPU of Celluclast 1.5 $\mathrm{L} / \mathrm{gTS}$ to $50 \mathrm{FPU}$ of Celluclast $1.5 \mathrm{~L} / \mathrm{gTS}$, the saccharification is slightly only affected, not exhibiting any statistically important difference, whereas, for enzymatic loadings from 100 FPU of Celluclast $1.5 \mathrm{~L} /$ gTS until $400 \mathrm{FPU}$ of Celluclast $1.5 \mathrm{~L} / \mathrm{g}$ TS the liberation of sugars is significantly increased, reaching the value 


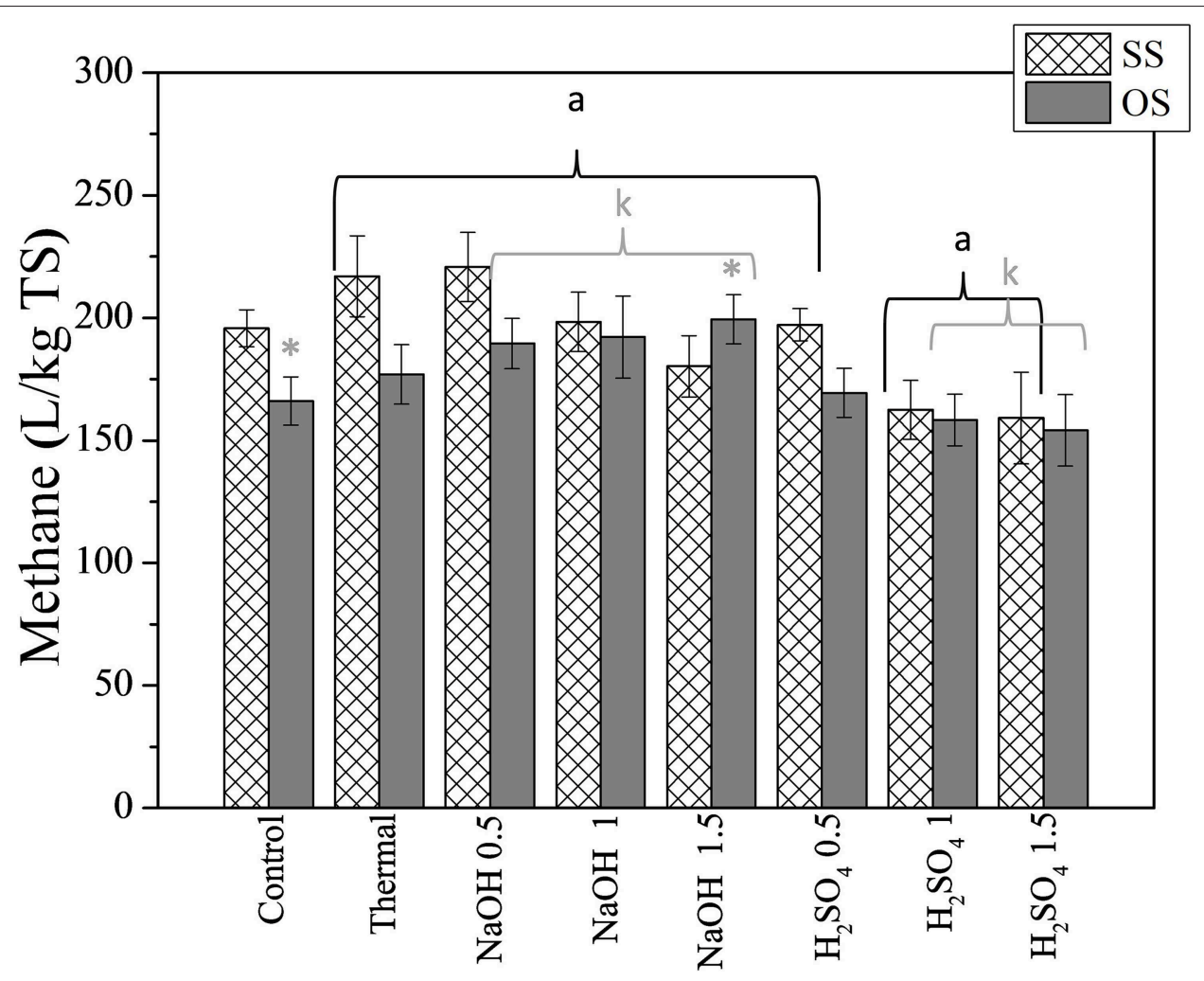

FIGURE 3 | The effect of thermochemical pretreatment on the methane potential of SS and OS. The results are mean \pm SD from six different measurements $(N=6)$ The statistical difference with the control (untreated biomass) is indicated by an asterisk above columns, whereas statistical difference among values is indicated by different letters above columns (Mann Whitney $u$-test).

of $363.10 \pm 11.08 \mathrm{~g}$ sugars $/ \mathrm{kg}$ TS SS. On the contrary, in the case of OS enzymatic loadings from 100 FPU of Celluclast 1.5 L/gTS until $400 \mathrm{FPU}$ of Celluclast $1.5 \mathrm{~L} / \mathrm{gTS}$ have an almost identical effect on the saccharification with values $167.46 \pm$ $6.50 \mathrm{~g}$ sugars $/ \mathrm{kg}$ TS OS and $186.93 \pm 13.85 \mathrm{~g}$ sugars $/ \mathrm{kg}$ TS OS, which were not evaluated as being significantly different. As it concerns the effect of the lower enzymatic loadings (20-50 FPU of Celluclast $1.5 \mathrm{~L} / \mathrm{gTS}$ ) on the hydrolysis of carbohydrates of OS, as shown by Figure 2 statistically significant difference is only observed for the lowest and highest value, meaning that the loadings of 30-50 FPU of Celluclast 1.5 L/gTS had actually the same effect on the saccharification of OS.

Taking into account all of the above, as well as the high cost of the commercial enzymes, the lower concentration of 30 FPU/g TS was considered to be preferable for the facilitation of saccharification of both substrates during the subsequent experiments of biofuels production. This was consistent with the study of Antonopoulou and Lyberatos (2013), where the effect of different enzyme concentrations (20,40,60, 80, 100, and $150 \mathrm{FPU}$ of Celluclast $1.5 \mathrm{~L} / \mathrm{gTS}$ ) on the saccharification of sweet sorghum biomass was investigated and the low concentration of $40 \mathrm{FPU} / \mathrm{gTS}$ was considered as optimum for the process.

\section{Biofuels Production Methane Production}

In Figure 3, the effect of thermochemical pretreatment methods on methane yields expressed in L methane per $\mathrm{kg}$ of TS of SS and OS, is illustrated. As shown, methane yields are quite high for control cultures for both substrates. Statistical significant differences among methane yields of control and pretreated biomass were only noticed for the highest acid treated SS (lower yields than control) and the alkaline treated OS with $1.5 \% \mathrm{NaOH}$ (higher yields than control). It is indeed true that the effect of thermochemical pretreatment on methane production is reported to be quite diverse for the different types of lignocellulosic feedstocks (Carrere et al., 2016). In general, alkaline pretreatment affects lignin and partially affects hemicellulose, increasing the accessibility of enzymes to the cellulose (Antonopoulou et al., 2015b). The effectiveness of alkaline treatment depends on the lignin content of the biomass (Carrere et al., 2016) and the pretreatment conditions (Antonopoulou et al., 2015a). Additionally, methanogenic microorganisms can exhibit high sensitivity to the inhibitory substances that are released during pretreatment, i.e., furaldehydes [furfural and 5-hydroxymethylfurfural (5HMF)] and acids (i.e., formic and acetic acid) that are mainly formed during acidic pretreated (Cao et al., 2012), and phenolic 


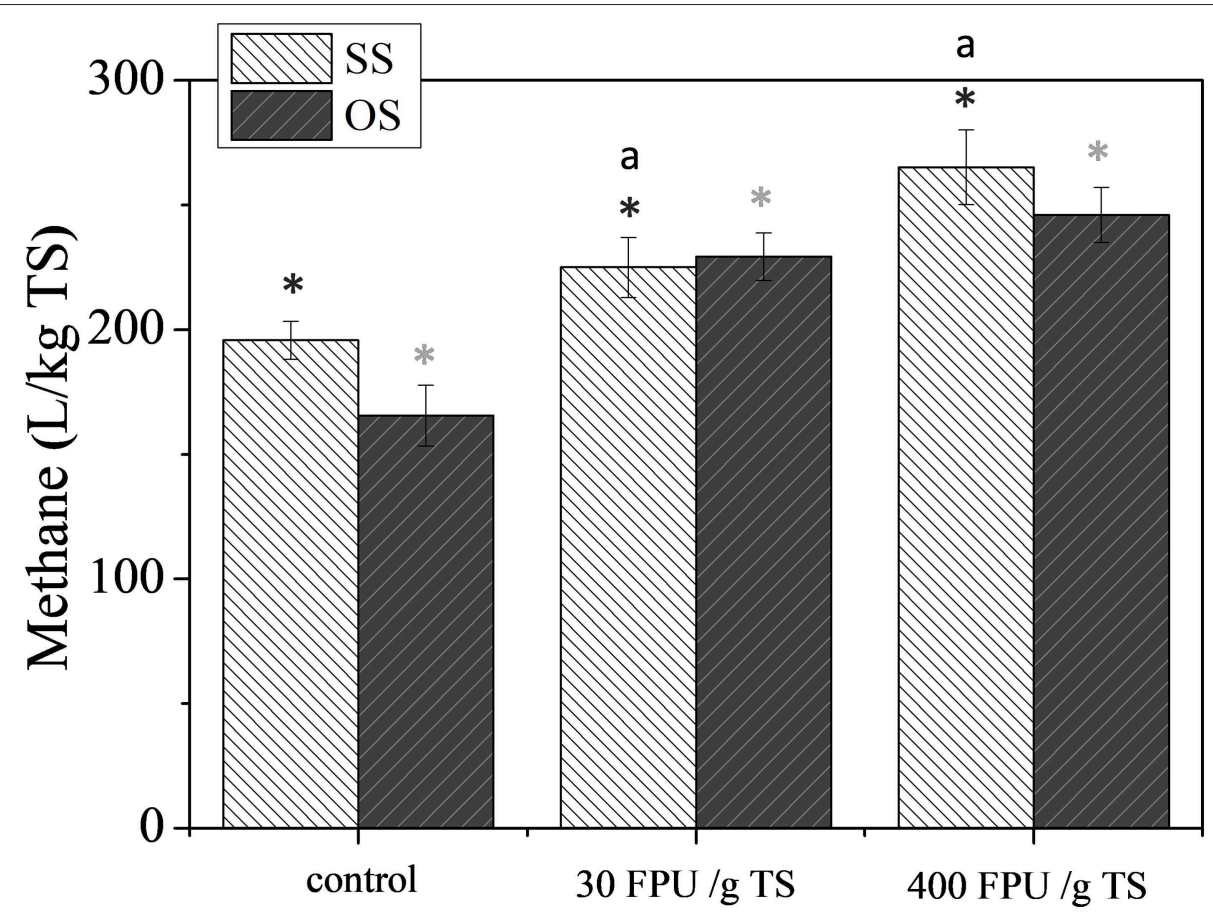

FIGURE 4 | The effect of enzymatic pretreatment on the methane potential of SS and OS. The results are mean \pm SD from six different measurements ( $N=6)$. The statistical difference with the control (untreated biomass) is indicated by an asterisk above columns, whereas statistical difference among values is indicated by different letters above columns (Mann Whitney $u$-test).

compounds mainly formed during alkaline pretreatment (Buranov and Mazza, 2008).

Thus, the lower methane potential at the higher acid loadings could be attributed to the formation of toxic compounds during pretreatment, as also reported by Antonopoulou and Lyberatos (2013) who applied acid pretreatment at room and high temperature on sweet sorghum biomass. In that study, it was indicated that acid treatment did not improve methane yields, neither when applied at room temperature nor at high temperatures, and that findings were attributed to the possible inhibition of methanogens by toxic compounds released during the pretreatment.

As it regards alkaline pretreatment, the lower methane yields attained at the higher alkaline concentration in the present study could thus be attributed to the formation of toxic compounds, which could probably be produced under severe conditions, due to the combination of high $\mathrm{pH}$ and high temperatures (Gossett et al., 1982). The lower methane potential observed at the higher $\mathrm{NaOH}$ loadings might also be attributed to the high sodium ion concentrations $\left(8.6 \mathrm{~g} \mathrm{Na}^{+} / \mathrm{L}\right)$ that could have a toxic or inhibitory effect on methanogens. Indeed, high concentrations (above $8 \mathrm{~g} / \mathrm{L}$ ) of $\mathrm{Na}^{+}$are reported to be inhibitory on the anaerobic digestion process (McCarty, 1964). A possible solution to that could be the use of another alkaline i.e., potassium or ammonia (Antonopoulou et al., 2015a).

To investigate the effect of enzymatic pretreatment on methane yield, the concentrations of 30 and 400 FPU/gTS of Celluclast $1.5 \mathrm{~L}$ and Novozyme (3:1) were tested (Figure 4 ). The enzymatic loading of $30 \mathrm{FPU} / \mathrm{gTS}$ was used as optimum based on the obtained results of saccharification, as well as economic viability of the overall process, while that of 400 FPU/gTS was used for comparison reasons, since it was the maximum concentration used for saccharification.

The experimental results revealed that the methane yield tends to increase with the addition of enzymes, with both enzymatic loadings leading to statistically significantly higher methane yields than those of control for both SS and OS. Especially for SS, a statistical difference was also noted for the BMP of cultures with different enzymatic loadings, which was not observed for OS. Specifically, the highest methane yields noted were $265.1 \pm 15.7$ and $245.9 \pm 11.0 \mathrm{~L} / \mathrm{kg}$ TS for SS and OS, respectively. The increase of the BMP of SS for higher enzymatic loading could be attributed to the considerably increased solubilisation of carbohydrates that occurred at the higher enzymatic concentrations, a result that was not noticed for OS (Figure 2).

From all of the above, it can be concluded that the enzymatic pretreatment was the most effective pretreatment scheme in terms of enhanced methane yields. This could be attributed to the fact that biological pretreatments are in general carried out at mild conditions, not accompanied by the release of compounds with toxic-inhibitory effect to methanogens (Alexandropoulou et al., 2017). From the other side, the high cost of commercial enzymes should be taken into account for the process scaleup, considering both economic (enzymes and energy costs) and technical (increase in methane yields) aspects. 


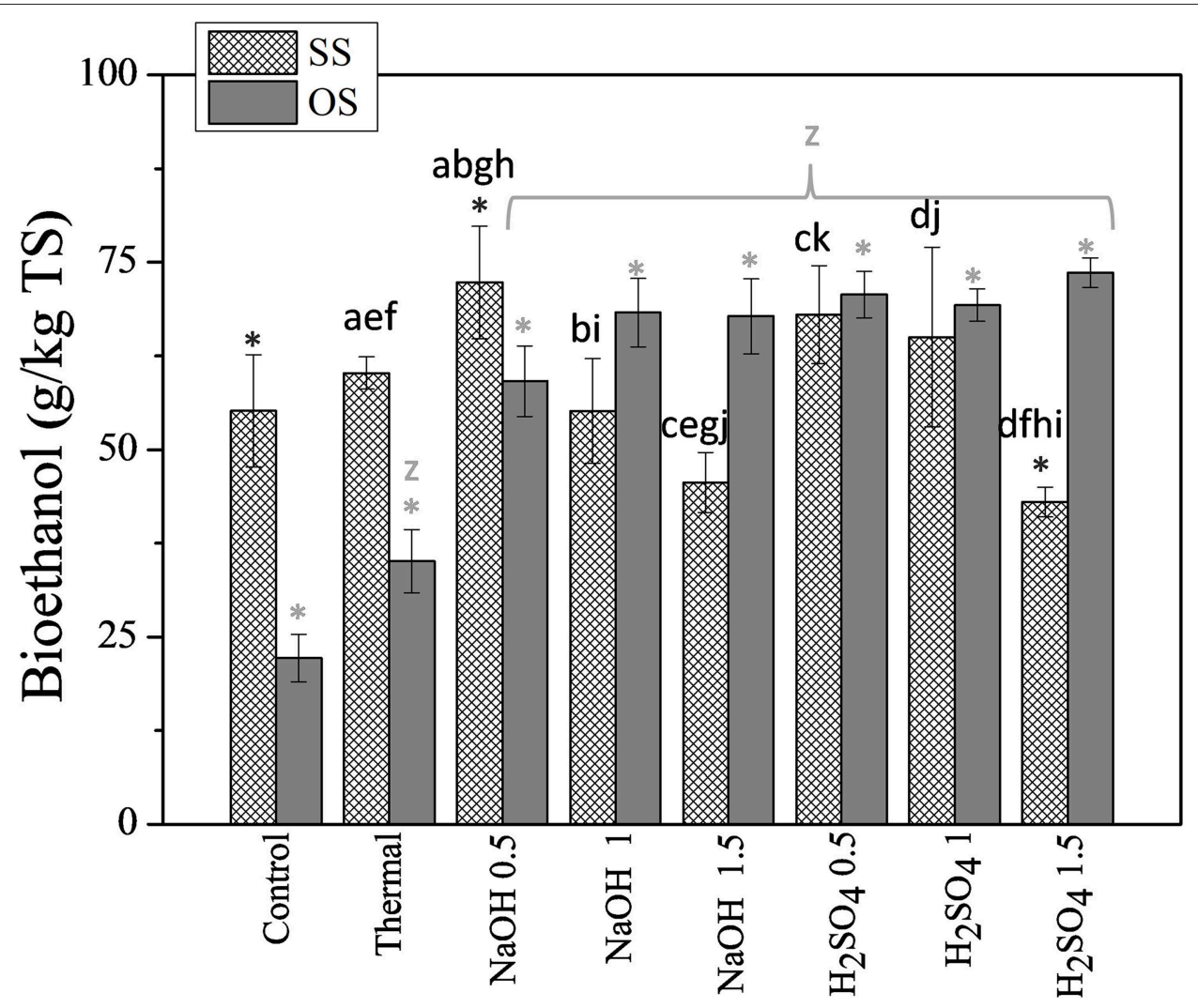

FIGURE 5 | The effect of thermochemical pretreatment on the ethanol yields of SS and OS using $P$. tannophilus. The results are mean \pm SD from six different measurements $(N=6)$. Asterisks above columns indicate statistical difference with the control (untreated biomass), whereas different letters above columns indicate statistical difference among values (Mann Whitney $u$-test).

\section{Bioethanol Production}

The whole slurries obtained of SS and OS pretreatments were assessed for ethanol production, using $P$. tannophilus and commercial enzymes [Celluclast 1.5L (30 FPU/g TS) and Novozyme 188 at a ratio of (3:1)], at simultaneous saccharification and fermentation (SSF) concept. The ethanol yields after $48 \mathrm{~h}$ of fermentation, expressed as $\mathrm{g} / \mathrm{kg}$ TS of SS or OS under different pretreatment conditions, are presented in Figure 5.

At a first glance, it can be noted that the effect of the type and concentration of chemical used on final ethanol production, is quite different for SS and OS. This can be attributed, as in the case of methane production, to the differences in the content of lignocellulose fractions of the two substrates, which can result in the generation of different types and amounts of compounds that are inhibitory for the metabolism of the yeast. As it regards the effect of pretreatment on the ethanol yields from OS, it was shown that all pretreatment types resulted in statistically significantly higher values than those of the control cultures (untreated OS), but also that the values obtained from thermochemical pretreatment were, in all cases, statistically significantly higher than those of the thermally pretreated OS. Different chemical agents and their concentration, on the other hand, did not seem to significantly affect ethanol production since the final yields were not actually statistically differentiated.

As it regards SS, the ethanol control culture was quite higher than that of control culture with OS $(55.2 \pm 7.5$ and $22.2 \pm 3.2 \mathrm{~g} / \mathrm{kgTS}$, respectively) indicating that a higher amount of carbohydrates is hydrolyzed and becomes available for fermentation for SS than for OS. This is in agreement with the saccharification results of the biomasses during enzymatic treatment (Figure 2). Alkaline pretreatment at the lowest concentration resulted in a higher ethanol yield. Thus, treatment with $0.5 \% \mathrm{w} / \mathrm{v} \mathrm{NaOH}$ led to the production $72.3 \pm$ $7.5 \mathrm{~g}$ ethanol $/ \mathrm{kg}$ TS, which was $31 \%$ higher than the respective of raw SS under SSF. Increasing $\mathrm{NaOH}$ loading, the ethanol production yields decreased, probably due to inhibition of P. tannophilus from the compounds realized during alkaline pretreatment. Similar results were obtained when using acid pretreatment, where $0.5 \% \mathrm{w} / \mathrm{v} \mathrm{H}_{2} \mathrm{SO}_{4}$ led to the production of $68.1 \pm 6.5 \mathrm{~g}$ ethanol $/ \mathrm{kgTS}$, while the addition of $1.5 \% \mathrm{w} / \mathrm{v}$ $\mathrm{H}_{2} \mathrm{SO}_{4}$ caused a decrease in the ethanol yield by $43.1 \pm$ $2.0 \mathrm{~g} / \mathrm{kgTS}$.

The ethanol yields of SS obtained in the present study are similar with the respective obtained by Antonopoulou et al. (2016), who investigated the effect of pretreatment on ethanol 
production from SS, of different origin, using the $\mathrm{C}_{5}$ sugarsconsuming yeast Pichia stipitis. Similarly, the results obtained for ethanol production of OS are in good agreement with those of the study of Senkevich et al. (2012), in which ethanol production from pretreated solid olive mill residues at similar conditions was assessed.

\section{CONCLUSIONS}

It was shown that acid pretreatment leads to higher saccharification of both substrates that were tested in present study, SS and OS, whereas the direct saccharification of alkaline pretreatment is considerably lower. Enzymatic pretreatment also enhanced the liberation of free sugars with increasing enzymatic loadings, being more effective in the hydrolysis of SS. In general, it was shown that the higher concentrations of $\mathrm{H}_{2} \mathrm{SO}_{4}$ and $\mathrm{NaOH}$ did not have a statistically significant effect on either the saccharification or the obtained methane and ethanol yields from each substrate. On the contrary, when comparing the effect of the same pretreatment method on SS and OS, in terms of either saccharification or biofuels yields, it is obvious that the results are differentiated considerably.

\section{REFERENCES}

Alexandropoulou, M., Antonopoulou, G., Fragkou, E., Ntaikou, I., and Lyberatos, G. (2017). Fungal pretreatment of willow sawdust and its combination with alkaline treatment for enhancing biogas production. J. Environ. Manage. 203, 704-713. doi: 10.1016/j.jenvman.2016.04.006

American Public Health Association, American Water Works Association, and Water Environment Federation. (1995). Standard Methods for the Examination of Water and Wastewater, ed M. A. Franson (Washington, DC: American Public Health Association).

Antonopoulou, G., Dimitrellos, G., Beobide, A. S., Vayenas, D., and Lyberatos, G. (2015b). Chemical pretreatment of sunflower straw biomass: the effect on chemical composition and structural changes. Waste Biomass Valor. 6, 733-746. doi: 10.1007/s12649-015-9388-x

Antonopoulou, G., Gavala, H. N., Skiadas, I. V., and Lyberatos, G. (2015a). The effect of aqueous ammonia soaking pretreatment on methane generation using different lignocellulosic biomasses. Waste Biomass Valor. 6, 281-291. doi: $10.1007 /$ s12649-015-9352-9

Antonopoulou, G., and Lyberatos, G. (2013). Effect of pretreatment of sweet sorghum biomass on methane generation. Waste Biomass Valor. 4, 583-591. doi: $10.1007 / \mathrm{s} 12649-012-9183-\mathrm{x}$

Antonopoulou, G., Vayenas, D., and Lyberatos, G. (2016). Ethanol and hydrogen production from sunflower straw: the effect of pretreatment on the whole slurry fermentation. Biochem. Eng. J. 116, 65-74. doi: 10.1016/j.bej.2016. 06.014

Buranov, A. U., and Mazza, G. (2008). Lignin in straw of herbaceous crops Ind. Crops Prod. 28, 237-259. doi: 10.1016/j.indcrop.2008.03.008

Cao, S., Pu, Y., Studer, M., Wyman, C., and Ragauskas, A. J. (2012). Chemical transformations of Populus trichocarpa during dilute acid pretreatment. RSC Adv. 2, 10925-10936. doi: 10.1039/C2RA22045H

Carrere, H., Antonopoulou, G., Affes, R., Passos, F., Battimelli, A., Lyberatos, G., et al. (2016). Review of feedstock pretreatment strategies for improved anaerobic digestion: from lab-scale research to full-scale application. Biores. Technol. 199, 386-397. doi: 10.1016/j.biortech.2015. 09.007

Ferro, M. D., Fernandes, M. C., Paulino, A. F. C., Prozil, S. O., Gravitis, J., Evtuguin, D. V., et al. (2015). Bioethanol production from steam explosion pretreated and alkaline extracted Cistus ladanifer (rockrose). Biochem. Eng. J. 104, 98-105. doi: 10.1016/j.bej.2015.04.009

\section{DATA AVAILABILITY STATEMENT}

The datasets generated for this study are available on request to the corresponding author.

\section{AUTHOR CONTRIBUTIONS}

GA, IN, and GL conceived and designed the experiments. GA and IN performed the experiments and analyzed the data. $\mathrm{AK}$ contributed to the characterization of substrates and the statistical analysis of data. IN wrote the paper.

\section{FUNDING}

We acknowledge support of this work by the project Research infrastructure for Waste Valorization and Sustainable Management of Resources, INVALOR (MIS 5002495) which is implemented under the Action for the Strategic Development on the Research and Technological Sector, funded by the Operational Programme Competitiveness, Entrepreneurship and Innovation (NSRF 2014-2020), and co-financed by Greece and the European Union (European Regional Development Fund).

Galbe, M., and Zacchi, G. (2007). Pretreatment of lignocellulosic materials for efficient bioethanol production. Adv. Biochem. Eng. Biotechnol. 19 41-65. doi: 10.1007/10_2007_070

Ghose, T. K. (1987). Measurement of cellulase activities. Pure Appl. Chem. 59, 257-268.

Gossett, J. M., Stuckey, D. C., Owen, W. F., Mccarty, P. L. (1982). Heat treatment and anaerobic digestion of refuse. J. Environ. Eng. Div. 108, 437-454. doi: 10.1351/pac198759020257

Josefsson, B. (1983). "Rapid spectrophotometric determination of total carbohydrates," in Methods of Seawater Analysis, eds K. Grasshoff, M. Ehrhardt, and K. Kremling (Verlag Chemie GmbH), 340-342.

Kumar, A. K., and Sharma, S. (2017). Recent updates on different methods of pretreatment of lignocellulosic feedstocks: a review. Biores. Bioproc. 4:7. doi: 10.1186/s40643-017-0137-9

McCarty, P. L. (1964). Anaerobic waste treatment fundamentals. Part III, toxic materials and their control. Pub. Works 95, 91-94.

Monlau, F., Barakat, A., Steyer, J.-P., and Carrère, H. (2012). Comparison of seven types of thermo-chemical pretreatments on the structural features and anaerobic digestion of sunflower stalks. Bioresour. Technol. 120, 241-247. doi: 10.1016/j.biortech.2012.06.040

Monte, L. S., Escócio, V. A., de Sousa, A. M. F., Furtado, C. R. G., Leite, M. C. A. M., Visconte, L. L. Y., et al. (2018). Study of time reaction on alkaline pretreatment applied to rice husk on biomass component extraction. Biomass Convers. Biorefinery 8, 189-197. doi: 10.1007/s13399-017-0271-9

Senkevich, S., Ntaikou, I., and Lyberatos, G. (2012). Bioethanol production from thermochemically pretreated olive mill solid residues using the yeast Pachysolen tannophylus. Glob. Nest J. 14, 118-124. doi: 10.30955/gnj.000861

Conflict of Interest: The authors declare that the research was conducted in the absence of any commercial or financial relationships that could be construed as a potential conflict of interest.

Copyright (c) 2019 Antonopoulou, Kampranis, Ntaikou and Lyberatos. This is an open-access article distributed under the terms of the Creative Commons Attribution License (CC BY). The use, distribution or reproduction in other forums is permitted, provided the original author(s) and the copyright owner(s) are credited and that the original publication in this journal is cited, in accordance with accepted academic practice. No use, distribution or reproduction is permitted which does not comply with these terms. 